\title{
Vitamin D3 Treatment for Locally Advanced Thyroid Cancer: A Case Report
}

\author{
MARIKO MORISHITA*,**, AKIRA OHTSURU**, ATSUSHI KUMAGAI*, HIROYUKI NAMBA*, \\ NORIKO SATO***, TOMAYOSHI HAYASHI*** AND SHUNICHI YAMASHITA*,** \\ *Department of Molecular Medicine, Atomic Bomb Disease Institute, Nagasaki University Graduate School of Biomedical Sciences, \\ Nagasaki 852-8523, Japan \\ **International Hibakusha Medical Center, Nagasaki University Hospital, Nagasaki 852-8501, Japan \\ ***Department of Pathology, Nagasaki University Hospital, Nagasaki 852-8501, Japan
}

\begin{abstract}
There are many intricacies in the surgical treatment of locally advanced thyroid cancer, including the medical management of the remaining functional organ and any cosmetic impairments, which are sometimes very difficult to manage and eventually carry a relatively high morbidity and mortality. Here, we report on a case of a 65-year-old female with an extremely locally-advanced thyroid cancer involving both lobes of the thyroid, blood vessels, trachea and esophagus. Despite the severity of her condition, oral administration of vitamin D3 (alphacalcido) has stalled both the tumor growth and further increases of serum thyroglobulin $(\mathrm{Tg})$ level, and has led to a good preservation of quality of life for the last two years. Several reports have previously demonstrated the efficacy of vitamin D3 to inhibit the proliferation of thyroid cancer cell lines in vitro, but clinical evidence has been limited so far. Therefore, this case report provides important evidence for the effectiveness of vitamin D3 therapy against advanced thyroid cancers.
\end{abstract}

Key words: Advanced thyroid cancer, Vitamin D3, Thyroglobulin, Dormancy

(Endocrine Journal 52: 613-616, 2005)

THE most radical treatment for thyroid cancer is surgical removal of the tumor. However, it is sometimes very difficult to assess whether such an operation is appropriate when the tumor is advanced and has invaded neighboring tissues such as esophagus, trachea, nerves and blood vessels, etc. Moreover, the surgery may sometimes lead to an unacceptable outcome with severe impairment of the patient's quality of life.

Several reports have already demonstrated that 1,25 dihydroxyvitaminD (calcitriol), an active metabolite of vitamin D3, exerts an antineoplastic effect on several cancers such as those of colon, prostate and breast [14]. In addition, vitamin D3 has been shown to inhibit

Received: April 12, 2005

Accepted: July 28, 2005

Correspondence to: Dr. Mariko MORISHITA, Department of Molecular Medicine, Atomic Bomb Disease Institute, Nagasaki University Graduate School of Biomedical Sciences, 1-12-4 Sakamoto, Nagasaki City, Nagasaki 852-8523, Japan the proliferation of various thyroid cancer cell lines in vitro $[5,6]$. Recently, Dackiw et al. reported that calcitriol administration reduced the tumor burden and inhibited metastatic growth in an animal model of thyroid cancer [7]. However, there are few clinical studies that have evaluated the effectiveness of vitamin D3.

In this report, we present a patient diagnosed with locally advanced thyroid cancer whose tumor growth has been stabilized for 2 years following treatment with a low dose of oral vitamin D3.

\section{Case Report}

A 65-year-old Japanese female first noticed a lump in her neck and difficulty swallowing in October 2002. She also suffered from hoarseness, aspiration of food and a weight loss of $14 \mathrm{~kg}$ (from 56 to $42 \mathrm{~kg}$ ) over 6 months. As the lump continued to enlarge, she was referred to our hospital for further evaluation and treat- 
ment in March 2003. We found nothing to suggest thyroid nodules in her past medical history. The lump in her neck was more than $10 \mathrm{~cm}$ in diameter and had poor mobility. Ultrasonography (US) and computed tomography (CT) scans of the neck showed a large thyroid tumor consisting of both small and large cysts and solid components with calcification. Furthermore, the tumor had invaded the other side of the thyroid, passing through the dorsal part of the trachea and involving the recurrent nerve, carotid artery and esophagus. Blood test results showed a normal level of thyroid hormone but significant elevation of thyroglobulin (Tg) (213.6 $\mu \mathrm{g} / \mathrm{l})$. Fine needle aspiration cytology of the tumor revealed thyroid papillary carcinoma (Fig. 1).

The patient consistently refused to undergo surgery to remove the tumor and involved tissues, although she was informed that the prognosis of her thyroid cancer would be poor without surgical treatment. To reduce the volume of the tumor, some fluid was aspirated from the cystic lesions of the tumor, after which she was able to breathe more easily and eat semi-solid food. Therefore, this aspiration procedure from the tumor was continued on an almost weekly basis, draining a volume of around $90-100 \mathrm{ml}$ each time. In addition, to further stabilize the cancer, the oral administration daily of $0.5 \mu \mathrm{g} /$ body of Alphacalcido (Alpharol ${ }^{\circledR}$ ), a precursor of 1 alpha, 25-dihydroxyvitamin D3, was started in June 2003. Informed consent was obtained from this patient and she was informed that Alphacalcido $\left(\right.$ Alpharol $^{\circledR}$ ) was commonly used to treat osteoporosis, but had not yet been approved officially as a treatment for thyroid cancer. Serum calcium level was within the normal range both before and after the Alphacalcido administration. Serum Tg level was $824.2 \mu \mathrm{g} / \mathrm{l}$ in May 2003 but decreased to $265 \mu \mathrm{g} / \mathrm{l}$ in July 2003. Tg level dropped further to $219 \mu \mathrm{g} / 1$ in February 2005. The general condition of the patient has been stable up to the present date, April 2005. CT scan showed no significant changes in the diameter of the tumor size, and no evidence of distant metastasis was found during this period (Fig. 2). Furthermore, weight loss, anemia and hypoproteinemia have been stabilized over these 2 years.

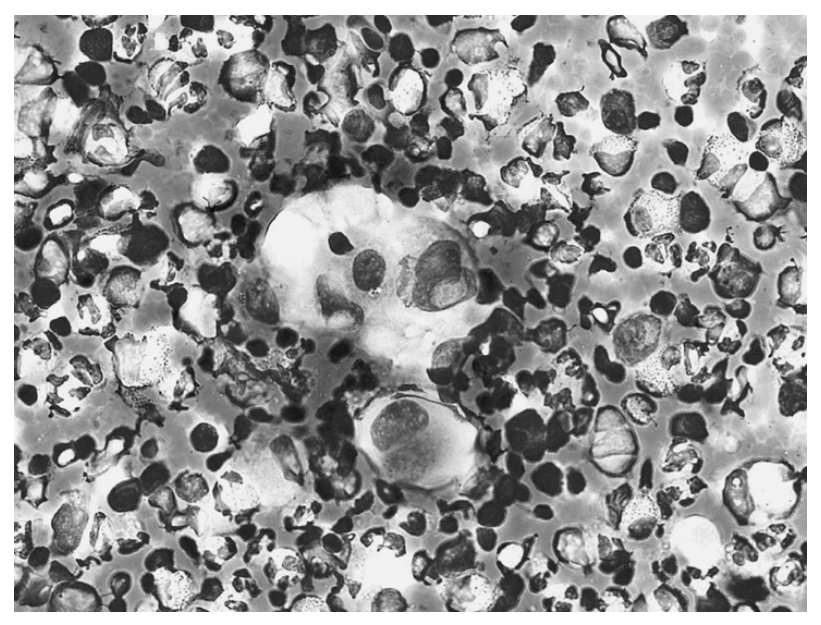

Fig. 1. Aspiration cytology presented abnormal cell clusters with large cells showing irregular nuclear size, high nucleocytoplasmic ratio, irregular nuclear membrane, increased chromatin and obvious nuclear cytoplasmic pseudoinclusion. (Giemsa stain, $\times 400$ )
(A)

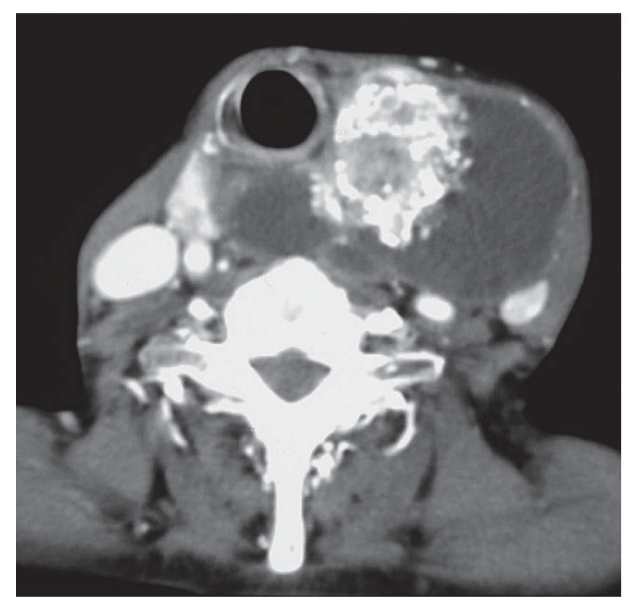

(B)

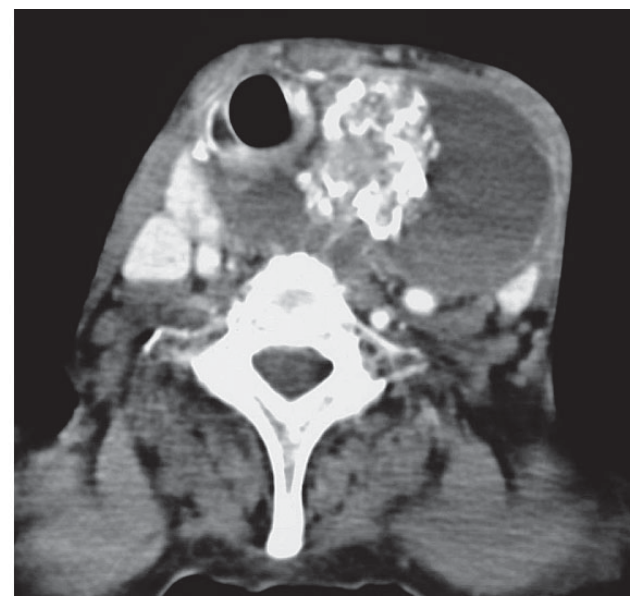

Fig. 2. CT of transversal section. Scans were carried out in April 2003 (A) and February 2005 (B). 


\section{Discussion}

Thyroid carcinomas exhibit a wide range of differentiation from indolent carcinomas such as micropapillary carcinoma diagnosed at autopsy, to the most aggressive human malignancies, anaplastic carcinoma. Differentiated thyroid cancers usually present a good prognosis after surgical removal of the tumor, but when the tumor has invaded blood vessels, nerves, esophagus and trachea, a complete excision may compromise their functionality as well as the safety of operation. In such cases, an alternative treatment would be desirable.

Recently, new therapies for recalcitrant thyroid cancer have been proposed. Gene therapies based on different strategies such as p53 reintroduction, suicide gene therapy or re-expression of the sodium iodide symporter (NIS) have shown some effectiveness in animal models, but the safety and efficacy of such therapies in man are still controversial [8-10]. Redifferentiation therapy using retinoic acid (RA) has also been attempted in vitro and in animal models, but its clinical effectiveness has yet to be demonstrated $[11,12]$. Immunotherapy using specific antigens such as CEA for medullary thyroid cancer has also been investigated in a phase I clinical trial, but its efficacy proved too limited for practical use [13]. Therefore, practical and effective therapies are still necessary for those thyroid cancers where surgical treatment is not possible.

The role of vitamin D3 in the modulation of proliferation and differentiation, the reduction in invasiveness and angiogenesis, and the induction of apoptosis has been identified in a variety of cancerous cell types, including those of breast, prostate and colorectal cancers [1-4]. In one study, large doses of calcitriol were required to obtain antineoplastic effects, however, in another study, a reduction in the level of prostate specific antigen was reported using a daily oral dose of 0.5 to $1.5 \mu \mathrm{g}$ of calcitriol in patients with prostate cancer $[14,15]$. Currently clinical trials are in progress to examine the effectiveness of 1,25-dihydroxyvitamin D3 (calcitriol) for prostate cancer, and the synergistic and/or additive effects of vitamin D3 with cytotoxic chemotherapies are also under investigation $[16,17]$.
In terms of thyroid cancer, there have been several reports on the efficacy of vitamin D3 to inhibit proliferation and to induce re-differentiation of thyroid cancer cell lines in vitro $[5,6]$. Recently, similar results have also been reported in animal models and thus clinical trials are anticipated for further investigation on the therapeutic role of vitamin D3 in thyroid cancer [7]. In our case, the dose of Alphacalcido (Alpharol ${ }^{\circledR}$ ) administered was low enough $(0.5 \mu \mathrm{g} /$ body/day $)$ to keep the serum levels of calcium and 1 alpha, 25-dihydroxyvitamin D3 within the normal range during the treatment. Thus, side effects of 1 alpha, 25-dihydroxyvitamin D3 such as hypercalcemia were avoided. On the other hand, the size of the solid components of the tumor barely changed during the period of vitamin D3 therapy, although no information on this aspect was available before the therapy was started.

In future, it is important to collect data of similar cases in order to establish the indications of vitamin D3 for induction of dormancy or stabilization of tumor growth in patients with thyroid cancer. A pooled analysis of multicenter joint studies under a common standard protocol should be formulated. The biopsy sample in our case was negative for BRAF mutation (data not shown), suggesting a relatively good prognosis. The relevance and significance of BRAF mutation in vitamin D3 treatment for thyroid cancer remains to be clarified $[18,19]$.

In summary, we report here a unique case of a locally advanced papillary carcinoma of the thyroid involving multiple tissues in the neck, where the tumor size was successfully stabilized following vitamin D3 treatment for 2 years. This case report provides a useful example of an alternative treatment for locally advanced thyroid cancer that was not amenable to surgical removal. However, more data must be collected before the efficacy of this treatment can be properly evaluated.

\section{Acknowledgements}

The authors would like to thank Dr. Nader Ghotbi and Dr. Sarah Forbes-Robertson for their helpful comments. 


\section{References}

1. Guyton KZ, Kensler TW, Posner GH (2003) Vitamin $\mathrm{D}$ and vitamin D analogs as cancer chemopreventive agents. Nutr Rev 61: 227-238.

2. Verlinden L, Verstuyf A, Van Camp M, Marcelis S, Sabbe K, Zhao XY, De Clercq P, Vandewalle M, Bouillon R (2000) Two novel 14-Epi-analogues of 1,25-dihydroxyvitamin D3 inhibit the growth of human breast cancer cells in vitro and in vivo. Cancer Res 15: 2673-2679.

3. Oades GM, Dredge K, Kirby RS, Colston KW (2002) Vitamin D receptor-dependent antitumour effects of 1,25-dihydroxyvitamin D3 and two synthetic analogues in three in vivo models of prostate cancer. BJU Int 90 : 607-616.

4. Evans SR, Shchepotin EI, Young H, Rochon J, Uskokovic M, Shchepotin IB (2000) 1,25-dihydroxyvitamin D3 synthetic analogs inhibit spontaneous metastases in a 1,2-dimethylhydrazine-induced colon carcinogenesis model. Int J Oncol 16: 1249-1254.

5. Okano K, Usa T, Ohtsuru A, Tsukazaki T, Miyazaki Y, Yonekura A, Namba H, Shindoh H, Yamashita S (1999) Effect of 22-oxa-1,25-dihydroxyvitamin D3 on human thyroid cancer cell growth. Endocr J 46: 243252.

6. Liu W, Asa SL, Fantus IG, Walfish PG, Ezzat S (2002) Vitamin D arrests thyroid carcinoma cell growth and induces p27 dephosphorylation and accumulation through PTEN/akt-dependent and -independent pathways. Am J Pathol 160: 511-519.

7. Dackiw AP, Ezzat S, Huang P, Liu W, Asa SL (2004) Vitamin D3 administration induces nuclear p27 accumulation, restores differentiation, and reduces tumor burden in a mouse model of metastatic follicular thyroid cancer. Endocrinology 145: 5840-5846.

8. Nagayama Y, Yokoi H, Takeda K, Hasegawa M, Nishihara E, Namba H, Yamashita S, Niwa M (2000) Adenovirus-mediated tumor suppressor p53 gene therapy for anaplastic thyroid carcinoma in vitro and in vivo. J Clin Endocrinol Metab 85: 4081-4086.

9. Nishihara E, Nagayama Y, Mawatari F, Tanaka K, Namba H, Niwa M, Yamashita S (1997) Retrovirusmediated herpes simplex virus thymidine kinase gene transduction renders human thyroid carcinoma cell lines sensitive to ganciclovir and radiation in vitro and in vivo. Endocrinology 138: 4577-4583.
10. Smit JW, Schroder-van der Elst JP, Karperien M, Que I, Romijn JA, van der Heide D (2001) Expression of the human sodium/iodide symporter (hNIS) in xenotransplanted human thyroid carcinoma. Exp Clin Endocrinol Diabetes 109: 52-55.

11. Schmutzler C, Kohrle J (2000) Retinoic acid redifferentiation therapy for thyroid cancer. Thyroid 10: 393 406.

12. Simon D, Korber C, Krausch M, Segering J, Groth P, Gorges R, Grunwald F, Muller-Gartner HW, Schmutzler C, Kohrle J, Roher HD, Reiners C (2002) Clinical impact of retinoids in redifferentiation therapy of advanced thyroid cancer: final results of a pilot study. Eur J Nucl Med Mol Imaging 29: 775-782.

13. Schott M, Seissler J, Lettmann M, Fouxon V, Scherbaum WA, Feldkamp J (2001) Immunotherapy for medullary thyroid carcinoma by dendritic cell vaccination. J Clin Endocrinol Metab 86: 4965-4969.

14. Osborn JL, Schwartz GG, Smith DC, Bahnson R, Day R, Trump DL (1995) Phase II trial of oral 1,25dihydroxyvitamin D (calcitriol) in hormone refractory prostate cancer. Urol Oncol 1: 195-198.

15. Beer TM, Myrthue A, Eilers KM (2005) Rationale for the development and current status of calcitriol in androgen-independent prostate cancer. World J Urol 23: 28-32.

16. Beer TM, Hough KM, Garzotto M, Lowe BA, Henner WD (2001) Weekly high-dose calcitriol and docetaxel in advanced prostate cancer. Semin Oncol 28: 49-55.

17. Beer TM, Myrthue A (2004) Calcitriol in cancer treatment: from the lab to the clinic. Mol Cancer Ther 3: 373-381.

18. Namba H, Nakashima M, Hayashi T, Hayashida N, Maeda S, Rogounovitch TI, Ohtsuru A, Saenko VA, Kanematsu T, Yamashita S (2003) Clinical implication of hot spot BRAF mutation, V599E, in papillary thyroid cancers. J Clin Endocrinol Metab 88: 4393-4397.

19. Nikiforova MN, Kimura ET, Gandhi M, Biddinger PW, Knauf JA, Basolo F, Zhu Z, Giannini R, Salvatore G, Fusco A, Santoro M, Fagin JA, Nikiforov YE (2003) BRAF mutations in thyroid tumors are restricted to papillary carcinomas and anaplastic or poorly differentiated carcinomas arising from papillary carcinomas. J Clin Endocrinol Metab 88: 5399-5404. 